\title{
Improving Submissions to Scholarly Journals via Peer Review
}

\author{
Elena Tikhonova ${ }^{1,2}$, Lilia Raitskaya ${ }^{3}$ \\ ${ }^{1}$ Peoples' Friendship University of Russia (RUDN University) \\ ${ }^{2}$ National Research University Higher School of Economics \\ ${ }^{3}$ Moscow State Institute of International Relations (MGIMO University) \\ Correspondence concerning this article should be addressed to Elena Tikhonova, National Research \\ University Higher School of Economics, 26 Shabolovka, Moscow, Russian Federation, 119049. \\ E-mail: etihonova@hse.ru
}

\begin{abstract}
Due to their commitment to better publishing standards and desire to improve their journals' academic reputation, editorial boards, editors, and editorial teams seek to refine submissions they receive. Though, the peer review process serves as a filtering and assessment system, it is believed to greatly contribute to better quality of scholarly journals. Based on the analysis of the peer review internationally, the JLE editors focus on the peer review in the Journal of Language and Education, sharing their experience with the JLE potential authors. The editorial contains some reflections on the efficacy of peer review in the JLE. Potential authors may find some tips as to how to interact with recommendations and criticism on part of their peer reviewers and to make their voices heard.
\end{abstract}

Keywords: peer review, peer reviewer, scholarly communication, scholarly journal, submission, original article, editor

\section{Peer Review as a Communication Platform and a Filtering System}

The present-time role of peer review process in scholarly journals is undoubtedly great, though it is changing to address the new challenges of the rapidly evolving scholarly communication. Peer review has been in existence for over three hundred years. Lately it has become a social institution to safeguard new contributions to science against fraudulent or fake research and lack of integrity at large.

Academic quality control is installed to filter all research publications. The traditional screening system embraces peer review and editing of all submissions without which scholarly journals cannot be considered a fully-fledged communication platform. Though "the editorial management is a crucial part of the publishing process" (Zheng, 2005), the peer review process is believed to be aimed at improving the accepted manuscripts. It might "contribute to the citedness of papers" (Rigby, 2018). Peer review is central to "the production of academic knowledge" (Rigby, 2018).

As the academia is a rather specific and narrow profession, peers act as the sole experts barring other social, but non-academic actors' interaction and interference. But academic peers are expected not only to assess manuscripts submitted to scholarly journals and publishers, but also to prove their verdict, pointing out mistakes and outlining omissions as well as suggesting some ways of correcting the drawbacks to improve the manuscripts at large.

Journal peer review seeks to decide whether to accept or reject a submission. Peer review is viewed as a decisionmaking process (Rigby, 2018). Validity of judgments in peer review is proved by the academic experience of reviewers, their publications, their influence in the field determined by the reputation of the journals they publish with and citedness of their research.

The efficacy of peer review is desirable, but it is still a disputed issue. The approaches are numerous, and sometimes they contradict each other. Every journal records cases when a peer reviewer's criticism may degrade 
some well-done research if blindly accepted by the author(s). Poor quality of peer review is often quoted as a major problem faced by journal editors (Jawaida, 2004).

In some settings, peer review can have little or no impact on the quality of journal papers. When the ratio of accepted manuscripts to incoming submissions is very low, i.e. few papers are accepted whereas a lot of submissions are made; the quality of a paper in such a journal remains nearly unchanged via the peer review process (Somerville, 2016). Most highly ranking journals fit this pattern, as they regularly receive many submissions, with their desk rejection and overall rejection levels being close to $80-90 \%$ of all the submitted papers. Such journals are in a lucky position as the best authors with high-quality research papers target this category of journals.

\section{Peer Review Stakeholders}

Stakeholders in the peer review process embrace authors, editors, and reviewers. Editorial boards are also widely involved in the process in most journals. The role and functions as well as goals of the stakeholders may sometimes be at variance. Editorial teams and boards are to guide the process in order to facilitate the review process communication. The more submissions a journal gets, the easier it selects relevant and solid papers for publication. But when a journal is relatively new, or is not indexed with the leading international databases, peer review helps a great deal to fine-tune the papers to be published.

Peer reviewers set the scene for authors of submissions. The verdict they pass is often determinant in accepting or rejecting a manuscript. To be more or less impartial, editors often seek to base their final decision on their reviewers' recommendations. Though, the final say is always with the editorial board. Authors at large appear to have not much impact on the manuscript acceptance. But if a journal editor, reviewers, and authors actively communicate regarding the submission, the authors' voice may matter a lot. Editors, boards, and reviewers are peers of authors. They are not controllers or otherwise superior to authors. The understanding of their functional positions as well as aspiration to publish a high-profile journal are prone to success. For a journal, to be successful implies being influential, open-minded, and unbiased.

Unfortunately, stakeholders are often inclined to "cut their way short":authors do their best to get their papers published without any amendments and revisions; reviewers insist on the revisions the way they see them, occasionally turning a deaf ear to authors; editors endeavor to get the incoming papers improved if these submissions are positively assessed. Editors are eager to publish high-profile papers without going beyond time schedules. Thus, personal motives often collide and bring the peer review process to a halt or to worse than expected results.

Traditional double blind peer review is a "time-tested method" (Das, 2016). It is being widely critiqued for great delays in completion, occasional prejudice, "inconsistencies amongst reviewers, ... lack of motivation of reviewers" (Das, 2016). It may also lead to failures to detect fraud.

In response, many new forms of peer review have emerged. Open peer review is making some headway in scholarly publishing. Some time ago this form came into existence when a few journals started experimenting with open peer review for articles. It has brought two meanings: transparency and participation (Peters, Brighouse, Tesar, Sturm, \& Jackson, 2020). Though some critics believe it also may result in inability to validate quality control (Das, 2016); open review is regularly compared with traditional double blind review. The efficacy of the new forms seems to be not much higher than that of double blind review (Shoham, \& Pitman, 2020). But open peer review "increases accountability of reviewers". In its turn, "accountability fosters greater cooperation" (Zhang, Smith, \& Lobo, 2020). But the most important feature of the emerging forms of peer review is brandnew ways of scholarly communication.

\section{Peer Review in the JLE}

The JLE sticks to double peer review (where both authors and reviewers are unaware of identities of each other) and open peer review (where identities of reviewers and authors are not concealed). Any author is entitled to opt for either of them. But the key stages are common for both forms. As for the JLE reviewers, only twenty percent of them opt for open review. But none has given their consent to publish their reports on the JLE site. 
When a manuscript enters its submission system via the JLE site, and unless it is desk rejected, it is assigned to two or three reviewers (See Exhibit 1). Prior to peer review, the JLE editorial board and team scrutinize the manuscript to save the reviewers' time. They seek to prove the identity of the relevant reviewers, check the information on their expertise. In most cases, JLE editors select experts in the field, having publications on the related themes. The JLE reviewers represent various nations and affiliations, preferably different from those of the submission authors.

\section{Exhibit 1}

The peer review process at the JLE

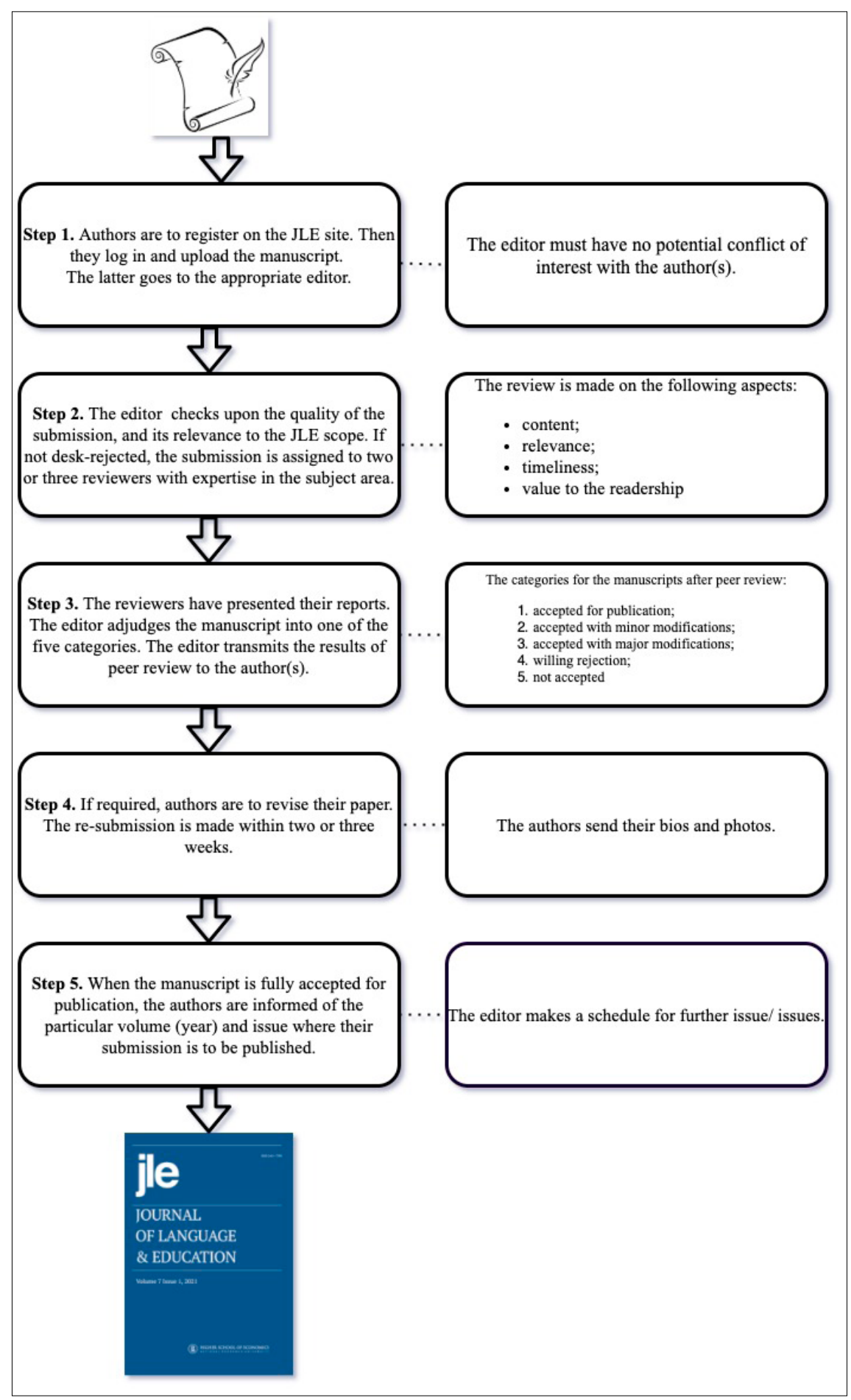


The problem typical of double-blind review is delays in submitting review reports. Sometimes our reviewers fail to reply within a few weeks. It is rather upsetting as it may disrupt the whole editorial cycle. As reviewers throughout the world are active researchers, sometimes they are short of time to response within the stated periods to enquiries. Luckily, most reviewers send their acceptance or rejection without delays. It is essential. All editors and reviewers realize that any new research is to come out as fast as possible, not to make the new knowledge obsolete. For medical sciences, it is also a matter of saving lives by introducing new methods of treatment (Andersen, Fonnes, \& Rosenberg, 2021).

Then the enquiries are sent to other reviewers. Occasionally, the initially assigned reviewers send their reports on a submission in several months. Such a submission may attract up to 4-5 review reports or more, collecting review reports at three or more rounds of the editorial cycle. In the JLE practice, there was a manuscript that got as many as nine review reports within several months. The authors should not be terrified of receiving many recommendations, even criticism from numerous reviewers. In general, the authors tend to revise their papers two or more times; they do it "in the light of feedback received on each occasion" (Price, 2014).

Submissions tend to have common mistakes or faults, mainly typical of each of the paper sections, including "title, abstract, key words, introduction, methods, results, discussion, conclusion, acknowledgments, references, tables, figures, cover letter, format and writing, submission processes, communication with the editor, revision processes, proof processes" (Johnson \& Green, 2009); and data presentation (Schriger, Sinha, Schroter, Liu, \& Altman, 2006). All authors should be concerned with details, including the scope of the journal, directions in the Author's Guide, structural patterns for the type of publication they are going to get published. Errors, misprints, inaccuracies may add to negative peer reviewers' reports (Schoenwolf, 2013). Occasionally, sections in the submissions contain inappropriate content. Their function will not realize.

There is one more disappointing practice when authors fail to upload some of the necessary files. Unfortunately, authors at large sometimes read the instructions for authors not very attentively. Some authors fail to comply with the JLE requirements (especially, requirements to enclose a cover letter and title page with the uploading manuscript).

The JLE reviewers contribute a lot to improve the manuscripts. Their recommendations are of great help and importance for the authors. The JLE editors are glad to realise that most of the suggested amendments are worth following. Critical thinking on part of all the concerned is essential in outlining the key points that can considerably improve the quality of the manuscript. The concepts and ideas of every author are self-important. Very rarely improvements may worsen a paper, as some reviewers suggest them solely based on their own views and expertise, failing to see the gist and rationale of the author(s).

As for double blind review, the JLE's experience is within the standard stereotyped view with all advantages (though sometimes subtle) and disadvantages (shared by most academics). With open review, fewer JLE authors opt for this form. In contacting some of those, we asked the question: "Why do you think that double blind review is more promising for your submission?" Some of the respondents think that their identity, including their affiliation, might distort their reviewers' attitude to their submission. Others note that they are not ready for this form of communication. At present, about 80 percent of all the JLE authors tend to choose double blind review. We guess that open review is still new to most researchers. It will take some time to adapt and realise the assets of open peer review. With open science being high on the global agenda, open review is certain to attract more supporters in the near future.

\section{Conclusion}

The JLE sees further studies of interrelation among peer review, its forms and the quality improvement of submissions as vital. JLE board members and editors strive to promote more efficient communication modes to attract active and promising researchers to communicate their cutting-edge ideas to the JLE readers. 
We trust that our potential authors are willing to share our commitment to more open, transparent, and unbiased scientific communication. Our editors do their best to rein in all inefficacies in the peer review process. But communication succeeds only when all participants are equally involved and contribute much.

Finally, we would like to express our gratitude to our reviewers for their dedication to science, their competence and invaluable contribution to the JLE development.

\section{Conflicts of interest}

The authors declare that they have no conflicts of interest.

\section{References}

Andersen, M. Z., Fonnes, S., \& Rosenberg, J. (2021). Time from submission to publication varied widely for biomedical journals: A systematic review. Current Medical Research and Opinion, 37(6), 985-993. https://doi. org/10.1080/03007995.2021.1905622

Das, M.G. (2016). "Peer review" for scientific manuscripts: Emerging issues, potential threats, and possible remedies. Medical Journal Armed Forces India, 72, 172-174. https://doi.org/10.1016/j.mjafi.2016.02.014

Jawaid, S. A. (2004). Problems faced by editors of peer reviewed medical journals. Saudi Medical Journal, 25(1 Suppl), S21-25.

Johnson, C., \& Green, B. (2009). Submitting manuscripts to biomedical journals: Common errors and helpful solutions. Journal of Manipulative and Physiological Therapeutics, 32(1), 1-12. https://doi.org/10.1016/j. jmpt.2008.12.002

Peters, M. A., Brighouse, S., Tesar, M., Sturm, S., \& Jackson, L. (2020). The open peer review experiment in Educational Philosophy and Theory (EPAT). Educational Philosophy and Theory,37(6), 975-983. https://doi.org /10.1080/00131857.2020.1846519

Price, B. (2014). Improving your journal article using feedback from peer review. Nursing Standard, 1987, 29(4), 43-50. https://doi.org/10.1080/00131857.2020.184651910.7748/ns.29.4.43.e9101

Rigby, J., Cox, D., \& Julian, K. (2018). Journal peer review: a bar or bridge? An analysis of a paper's revision history and turnaround time, and the effect on citation. Scientometrics, 114, 1087-1105. https://doi.org/10.1007/ s11192-017-2630-5

Schoenwolf, G. C. (2013). Getting published well requires fulfilling editors' and reviewers' needs and desires. Development Growth and Differentiation, 55(9), 735-743. https://doi.org/10.1111/dgd.12092

Schriger, D. L., Sinha, R., Schroter, S., Liu, P. Y., \& Altman, D. G. (2006). From submission to publication: A retrospective review of the tables and figures in a cohort of randomized controlled trials submitted to the British medical journal. Annals of Emergency Medicine, 48(6), 750-756.e21. https://doi.org/10.1016/j. annemergmed.2006.06.017

Shoham, N., \& Pitman, A. (2020). Open versus blind peer review: Is anonymity better than transparency? BJPsych Advances, 27(4), 247-254. https://doi.org/doi:10.1192/bja.2020.61

Steer, P. \& Ernst, S. (2021). Peer review: Why, when and how. International of Cardiology Congenital Heart Disease, 2, 100083. https://doi.org/10.1016/j.ijcchd.2021.100083

Zhang, D., Smith, R., \& Lobo, S. (2020). Should you sign your reviews? Open peer review and review quality. Industrial and Organizational Psychology, 13(1), 45-47. https://doi.org/10.1017/iop.2020.5

Zheng, J. (2005). Try to improve journal quality by improving standards and editing process. Shanghai Kou Qiang Yi Xue = Shanghai Journal of Stomatology, 14(2), 97-98. 